\title{
PREPARATION AND EVALUATION OF DROTAVERINE HCL ORAL DISINTEGRATING TABLETS USING SOLID MIXTURE TECHNIQUE
}

\author{
KURALLA HARI ${ }^{1 *}$, SARIPILLI RAJESWARI ${ }^{1}$, KOLAPALLI VENKATA RAMANA MURTHY²
}

${ }^{1}$ Department of Pharmaceutical Technology , Maharajah's College of Pharmacy, Phool Baugh, Vizianagaram, Andhra Pradesh, India. ${ }^{2}$ Department of Pharmaceutical Technology, A. U. College of Pharmaceutical Sciences, Andhra University, Visakhapatnam, Andhra Pradesh, India. Email: kuralla0205@gmail.com

Received: 22 January 2018, Revised and Accepted: 13 March 2018

ABSTRACT

Objective: The objective of this study is to formulate orally disintegrating taste masked tablets of drotaverine $\mathrm{HCl}$ using solid mixture technique.

Methods: Taste masked drug-polymer solid mixtures of drotaverine $\mathrm{HCl}$ were prepared by using hydroxypropyl methylcellulose (HPMC) 3 cps and rxcipient ${ }^{\circledR}$ FM1000/calcium silicate (rxcipient) as carriers employing kneading method using varying drug-polymer ratios of 1:1, 1:5, 1:7.5, and 1:9. Prepared drug-polymer mixtures evaluated for taste masking, and the ratio of drug-polymer is optimized. The granules and tablets prepared with optimized drug-polymer ratio were evaluated for pre- and post-compression parameters, in vitro dissolution studies, Fourier-transformation infrared spectroscopy (FTIR), differential scanning calorimetry (DSC), and X-ray diffractometry (XRD) studies.

Results: The drug:polymer ratios 1:7.5 with rxcipient and 1:9 with HPMC were optimized based on taste evaluation. The pre-compression results showed that all the formulae have good flow properties. The post-compression evaluations showed that all the formulae met the specifications of orally disintegrating tablets. From all the prepared taste masked drotaverine $\mathrm{HCl}$ tablets, R10 formulation consisting of $4 \%$ croscarmellose sodium and $\mathrm{H} 9$ formulation consisting of $3 \%$ croscarmellose sodium, 3\% sodium starch glycolate, and 2\% microcrystalline cellulose shown more than $99 \%$ drug release in $60 \mathrm{~min}$, and both the formulations showed better taste masking and were meting oral disintegrating tablet (ODT) parameters. The optimized formulation was characterized by FTIR, DSC, and XRD studies and found no incompatibility.

Conclusion: The results demonstrated that the prepared drotaverine HCl ODT showed better taste masking and meeting the parameters of ODT formulations R10 and H9. The present solid mixture technique can be effectively used for taste masking.

Keywords: Drotaverine $\mathrm{HCl}$, Hydroxypropyl methylcellulose, Rxcipient ${ }^{\circledR}$ FM1000, Solid mixture, Taste masking, oral disintegrating tablet.

(C) 2018 The Authors. Published by Innovare Academic Sciences Pvt Ltd. This is an open access article under the CC BY license (http://creativecommons. org/licenses/by/4. 0/) DOI: http://dx.doi.org/10.22159/ajpcr.2018.v11i6.24867

\section{INTRODUCTION}

Drotaverine $\mathrm{HCl}$ is a benzylisoquinoline derivative, which causes relaxation of smooth muscle that suppresses pain associated with spasm caused by smooth muscle contraction. Drotaverine $\mathrm{HCl}$ is sparingly soluble drug having a very bitter taste, and patients are reluctant to its taste when ordinary tablet is kept on tongue during swallowing. Hence, there is a poor patient compliance of using drotaverine $\mathrm{HCl}$ which necessitates the masking of its bitter taste during administration and improvement in its solubility and dissolution rate for patient compliance and improved bioavailability [1]. In this technology, the disintegration step will be completed in the oral cavity such that dissolution can be initiated in the stomach, thereby improving the efficacy of the drug. However, taste of the drug plays a vital role in the success of this technique as the disintegration occurs in the mouth. In case of drotaverine $\mathrm{HCl}$, simple technology of oral disintegrating tablet (ODT) is not suitable, and technologies that are suitable for improving both taste and disintegration rate are necessary. Earlier workers reported on taste masking of drotaverine $\mathrm{HCl}$ using approaches such as solid dispersion, drug coating, complexation with polymers, and coprocessing with superdisintegrants [2-6]. There are no reports cited earlier for the applicability of ODT technology for drotaverine $\mathrm{HCl}$. The applicability of techniques such as sublimation and solid mixtures was tried for drugs such as fosinopril, fenofibrate, levocetirizine dihydrochloride, and itraconazole in the design of ODT [7-12]. Hence, in the present investigation, it is proposed to prepare taste masked ODT of drotaverine $\mathrm{HCl}$ using solid mixture technique using hydroxypropyl methylcellulose (HPMC) and rxcipient as carriers employing kneading method with a disintegration time of $<1 \mathrm{~min}$ with complete drug release in 30-60 min.

\section{MATERIALS AND METHODS}

Materials

Drotaverine $\mathrm{HCl}$ was purchased from Biocon Ltd.; HPMC 3cps and rxcipient ${ }^{\circledR}$ FM1000 were gifted by Dr. Reddy's Laboratories; Croscarmellose sodium, Crospovidone, mannitol, Aspartame, Microcrystalline cellulose, sodium starch glycolate, PVPK-30, and magnesium stearate all are of analytical grade.

Preparation of drug-polymer solid mixture by kneading method for taste masking

Drug-carrier ratios of 1:1,1:5, 1:7.5, and 1:9 were used for the preparation of solid mixtures for both carries, i.e., HPMC and rxcipient. The materials were passed through sieve \#40. Drug-carrier were weighed and mixed in a mortar thoroughly, and sufficient quantity of isopropyl alcohol was added to the powder blend to form a paste and was triturated for 20$30 \mathrm{~min}$. The resultant wet mass of solid mixture was dried in a hot air oven for $30-60 \mathrm{~min}$ at $40^{\circ} \mathrm{C}$. The dried mass was pulverized in mortar and passed through sieve \#30 to obtain the powder. The prepared mixture was stored in airtight container till further use.

Evaluation and optimization of the drug-carrier powder for taste masking

The powder prepared by solid mixture was subjected to the evaluation of masking of bitterness in human volunteers as referred earlier. The optimized taste masked solid mixture was used for compressing ODT.

Preparation of taste masked drotaverine HCI ODT

Wet granulation technique was used for the compression of drotaverine $\mathrm{HCl}$ rxcipient powder, whereas direct compression was used for 
drotaverine $\mathrm{HCl} \mathrm{HPMC}$ powder. Drug-carrier solid mixture equivalent to $40 \mathrm{mg}$ of drotaverine $\mathrm{HCl}$ was compressed into tablets.

\section{Compression of drug-rxcipient solid mixture by wet granulation technique}

All the excipients were passed through Sieve \#40. The formula used for the compression of tablets for drotaverine HCl-rxcipient is shown in Table 1. Solid mixture, super disintegrant, and half the quantity of mannitol were weighed and mixed in a mortar in geometric progression to form uniform powder mixture. Wet granulation was done by adding 20\% w/v PVP K 30 in isopropyl alcohol to form wet mass. The wet mass was passed through sieve \#16 (aperture $1180 \mu \mathrm{m}$ ASTM) and dried at $40^{\circ} \mathrm{C}$. The dried granules were passed through Sieve \#18 and blended with a remaining quantity of mannitol, sweetener, and magnesium stearate in a poly bag. The obtained granules were evaluated for flow properties (angle of repose, Hausner ratio, and compressibility index). The granules were compressed on Karnavati12 station Rotary Tablet Compression Machine using $12 \mathrm{~mm}$ concave punches.

\section{Compression of drug-HPMC solid mixture by direct compression} technique

The formula used for the preparation of tablets using HPMC solid mixtures is shown in Table 2. All the excipients were passed through Sieve \#40. All the ingredients were weighed and mixed in geometric progression and evaluated for flow properties. The tablets were prepared using Karnavati12 station Rotary Tablet Compression Machine with $12 \mathrm{~mm}$ concave punches.

\section{Evaluation of granules}

The prepared granules were evaluated for flow properties such as angle of repose, compressibility index, and Hausner ratio.

\section{Angle of repose}

It was determined by the fixed funnel and free-standing cone method. A powder funnel in which the end of the stem is perpendicular to its axis of symmetry was fixed at a given height $(\mathrm{h})$ above the graph paper placed on a flat horizontal surface. The material was carefully poured through the funnel until the apex of the conical pile just touched the tip of the funnel. The radius (r) of the base of the pile was determined and the tangent angle of repose $(\theta)$ was calculated using the Equation $1[13,14]$.

$$
\operatorname{Tan} \theta=\frac{\mathrm{h}}{\mathrm{r}}
$$

\section{Carr's index}

Powder/granules were accurately weighed, transferred into a $100 \mathrm{~mL}$ measuring cylinder, and placed on to the tapped density tester and subjected to USP II method, i.e., 250 drops per minute with a drop height of $3 \pm 0.3 \mathrm{~mm}$ for 250 tappings. Volume $\left(\mathrm{V}_{t}\right)$ of the powder bed was measured after 500 tapings. The tapping was repeated for additional 750 times and volume was noted as $V_{b}$. If the difference between the two volumes is $<2 \%$, then $V_{t}$ is the final tapped density else it is repeated for another 1250 taps. It is calculated by the Equation $2[15,16]$

$$
\% \mathrm{CI}=\frac{\text { Tapped density -bulk density }}{\text { Tapped density }} \times 100
$$

\section{Hausner ratio}

Hausner ratio is related to interparticulate friction and as such could be used to predict powder flow properties. The powder with low interparticle friction such as coarse spheres has ratios of approximately 1.2, whereas more cohesive, less free-flowing powders such as flakes have Hausner ratio >1.6. It is calculated by the Equation $3[15,16]$.
Hausner ratio $=\frac{\text { Tapped density }}{\text { Untapped density }}$

\section{Evaluation of the tablets}

The compressed tablets were evaluated for general appearance, hardness, thickness, uniformity of weight, friability, uniformity of content, in vitro disintegration test, fineness of dispersion, in vitro dispersion, wetting time, in vitro dissolution, in vivo disintegration, taste evaluation, and drug excipients compatibility studies.

\section{General appearance}

Five tablets were selected randomly and evaluated for color and shape.

\section{Hardness}

The hardness of tablets is determined using Monsanto hardness tester. It is expressed in $\mathrm{Kg} \mathrm{cm}^{-2}(\mathrm{n}=5)$.

\section{Thickness}

Thickness is measured in mm using Vernier calipers and recorded $(n=5)$.

\section{Uniformity of weight}

Twenty tablets were selected at random and weighed individually, and average weight was calculated as per IP. The mean and the standard deviation were determined [16].

\section{Friability test}

Friability test was carried out in Roche friabilator according to IP. The percentage loss in weight (F) was calculated by the Equation 4 . The limit for friability is $<1 \%$ [17]

$$
\mathrm{F}=\left[1-\frac{\mathrm{w}}{\mathrm{w}_{0}}\right] \times 100
$$

\section{Fineness of dispersion}

This test is applicable to dispersible tablets only. It is an assessment of the grittiness which arises due to disintegration of the tablet into coarse particles. The test is performed by placing two tablets in $100 \mathrm{~mL}$ water and stirring it gently until the tablets get completely disintegrated. The formulation is considered to form a smooth dispersion if the complete dispersion passes through a sieve screen with a nominal mesh aperture of $710 \mu \mathrm{m}$ (Sieve \#22 IP standard) without leaving any residue on the mesh $(n=2)[17]$.

\section{Uniformity of content}

Ten tablets were taken randomly. All the tablets were crushed separately to a fine powder, and each tablet analyzed individually for drug content. Powder of each tablet was taken into a $100 \mathrm{~mL}$ volumetric flask. $50 \mathrm{~mL}$ of $0.1 \mathrm{~N} \mathrm{HCl}$ was added, shaken for $30 \mathrm{~min}$, and was made to volume with $0.1 \mathrm{~N} \mathrm{HCl}$ and filtered. $1 \mathrm{~mL}$ of the filtrate was taken into $10 \mathrm{~mL}$ volumetric flask and volume was made up to mark with $0.1 \mathrm{~N}$ $\mathrm{HCl}$. The absorbance was measured at $303 \mathrm{~nm}$ using ultraviolet (UV) spectrophotometer. Each tablet should contain not $<85 \%$ and not more than $115 \%$ of the labeled claim [16].

\section{In vitro dispersion time (with simulated salivary fluid)}

This test was performed to ensure disintegration of tablets in the salivary fluid if it is to be used as an orodispersible tablet. In vitro dispersion time was measured by dropping a tablet in a measuring cylinder containing $6 \mathrm{~mL}$ of simulated salivary fluid of $\mathrm{pH}$ 6.8. Three tablets from each formulation were randomly selected and in vitro dispersion time was performed [18]

\section{In vitro disintegration test}

Simulated salivary fluid is prepared by dissolving $13.872 \mathrm{~g}$ of potassium dihydrogen phosphate, $35.084 \mathrm{~g}$ of disodium hydrogen phosphate 
in sufficient water, and was made up to $1000 \mathrm{~mL}$. Finally, the $\mathrm{pH}$ was adjusted to 6.8 with $\mathrm{NaOH}$ solution. The test was performed to ensure disintegration of tablets as per IP in simulated salivary fluid at $37^{\circ} \mathrm{C}$. To be in compliance with the IP standards, dispersible tablets must disintegrate within 3 min [19].

\section{Wetting time}

Wetting time corresponds to the time taken for the tablet to disintegrate when kept motionless on the tissue paper in a Petri dish. This method will duplicate the in vivo disintegration, as the tablet is motionless on the tongue. Wetting time was measured by placing a tablet on a piece of tissue paper folded twice and was placed in a small Petri dish containing $6 \mathrm{~mL}$ of simulated saliva $\mathrm{pH} 6.8$, and the time for complete wetting was measured. Five tablets from each batch were used [20]

\section{In vitro dissolution studies}

The release of drotaverine $\mathrm{HCl}$ from prepared tablets was studied in $0.1 \mathrm{~N} \mathrm{HCl}$ using USP Type II apparatus. $900 \mathrm{~mL}$ of $0.1 \mathrm{~N} \mathrm{HCl}$ solution was used as the dissolution medium for drug release studies. The paddle rotation was adjusted to $50 \mathrm{rpm}$ and the bath temperature at $37 \pm 0.5^{\circ} \mathrm{C}$ was maintained throughout the dissolution test. Aliquots of $5 \mathrm{~mL}$ of the dissolution medium were withdrawn at appropriate time intervals (5, $10,15,30,45,60,90$, and $120 \mathrm{~min}$ ). The volume withdrawn at each time interval was replaced by the same quantity of the fresh dissolution medium maintained at $37 \pm 0.5^{\circ} \mathrm{C}$. The samples were suitably diluted with $0.1 \mathrm{~N} \mathrm{HCl}$ solution and analyzed at $303 \mathrm{~nm}$ using UV-visible spectrophotometer against the blank.

\section{In vivo disintegration time and taste evaluation}

The study protocol was approved from Andhra University Institutional Ethics Committee vide approval No.53 dated 05.07.2012. For in vivo disintegration test, five healthy human volunteers were selected. Before the test, all the volunteers were asked to rinse their mouth with distilled water [21]. Each of the five subjects was given a tablet. The tablets were placed on the tongue and immediately the time was recorded. It was expressed in seconds. The subjects were asked to spit out the content of the oral cavity after tablet disintegration and rinse their mouth with distilled water. The swallowing of the saliva was prohibited during the test and also saliva was rinsed from the mouth after each measurement. Three trials were performed with 2 -day interval between trials. The test results were presented as mean value.

Taste evaluation was done on five volunteers using time-intensity method. One tablet was held in mouth and bitterness levels were recorded instantly at $10 \mathrm{~s}, 30 \mathrm{~s}$, and $1 \mathrm{~min}$, and the bitterness levels, grittiness, and numbness levels are noted and recorded [22].

\section{Drug-excipient compatibility studies}

The optimized formulations were evaluated for drug excipient interaction studies through differential scanning calorimetry (DSC), $\mathrm{X}$-ray diffractometry (XRD), and Fourier-transformed infrared (FTIR) spectroscopy.

$D S C$

DSC was performed utilizing DSC Q20 Universal V4.5A TA Instruments. Samples were allowed to equilibrate for $1 \mathrm{~min}$ and then heated in an atmosphere of nitrogen over a temperature range from 0 to $300^{\circ} \mathrm{C}$. Thermograms were obtained using TA Instruments universal analysis software 2000.

\section{$X R D$}

The samples were recorded on XRD (PW 1729, Philips, Amsterdam, Netherlands). XRD patterns were recorded using monochromatic $\mathrm{Cu}$ $\mathrm{K} \alpha$ radiation with Ni filter at a voltage of $40 \mathrm{kV}$ and a current of $30 \mathrm{~mA}$ between $10^{\circ}$ and $80^{\circ} 2 \theta$ values. The data were processed with the software Diffrac Plus V1.01.

\section{FTIR spectroscopy}

FTIR spectra can be used to detect drug-excipient interactions by following the shift in vibrational or stretching bands of key functional groups. $\mathrm{KBr}$ pressed pellet technique was used in the preparation of pellet. The resultant pellet was kept in the IR chamber, and the IR spectra of the mixtures were recorded on a Bruker FTIR spectrophotometer equipped with Opus software.

Table 1: Formulae of drotaverine $\mathrm{HCl}$ ODT using drotaverine HCl-rxcipient solid mixture

\begin{tabular}{|c|c|c|c|c|c|c|c|c|c|c|c|}
\hline Ingredient (mg) & R1 & $\mathbf{R 2}$ & R3 & R4 & R5 & R6 & R7 & $\mathbf{R 8}$ & R9 & R10 & R11 \\
\hline $\begin{array}{l}\text { Drotaverine } \mathrm{HCl} \text {-rxcipient solid mixture (1:7.5) } \\
\text { equivalent to } 40 \mathrm{mg} \text { of drug }\end{array}$ & 340 & 340 & 340 & 340 & 340 & 340 & 340 & 340 & 340 & 340 & 340 \\
\hline Mannitol & 154 & 149 & 154 & 149 & 154 & 149 & 160 & 154 & 149 & 143 & 137 \\
\hline Crospovidone & - & - & - & - & 16.5 & 22 & - & - & - & - & - \\
\hline Croscarmellose sodium & 16.5 & 22 & - & - & - & - & 5.5 & 11 & 16.5 & 22 & 27.5 \\
\hline Sodium starch glycollate & - & - & 16.5 & 22 & - & - & - & - & - & - & - \\
\hline Aspartame & 18 & 18 & 18 & 18 & 18 & 18 & 18 & 18 & 18 & 18 & 18 \\
\hline PVP K-30 & 16.5 & 16.5 & 16.5 & 16.5 & 16.5 & 16.5 & 22 & 22 & 22 & 22 & 22 \\
\hline Magnesium stearate & 5 & 5 & 5 & 5 & 5 & 5 & 5 & 5 & 5 & 5 & 5 \\
\hline Total weight (mg) & 550 & 550 & 550 & 550 & 550 & 550 & 550 & 550 & 550 & 550 & 550 \\
\hline
\end{tabular}

ODT: Oral disintegrating tablet

Table 2: Formulae of drotaverine HCl ODT using drotaverine HCl-HPMC solid mixture

\begin{tabular}{|c|c|c|c|c|c|c|c|c|c|}
\hline Ingredient (mg) & H1 & $\mathbf{H} 2$ & H3 & H4 & H5 & H6 & H7 & H8 & H9 \\
\hline $\begin{array}{l}\text { Drotaverine } \mathrm{HCl} \text {-HPMC solid mixture (1:9) equivalent to } \\
40 \mathrm{mg} \text { of drug }\end{array}$ & 400 & 400 & 400 & 400 & 400 & 400 & 400 & 400 & 400 \\
\hline Croscarmellose sodium & 11 & 16.5 & 22 & 27.5 & 16.5 & 16.5 & 27.5 & 16.5 & 16.5 \\
\hline Mannitol & 115 & 109 & 104 & 98 & 92 & 92 & 70 & 75.5 & 81 \\
\hline Aspartame & 20 & 20 & 20 & 20 & 20 & 20 & 20 & 20 & 20 \\
\hline Sodium starch glycollate & - & - & - & - & - & 16.5 & 27.5 & 16.5 & 16.5 \\
\hline Crospovidone & - & - & - & - & 16.5 & - & - & - & - \\
\hline Magnesium stearate & 4 & 4.5 & 4 & 4.5 & 5 & 5 & 5 & 5 & 5 \\
\hline Total weight (mg) & 550 & 550 & 550 & 550 & 550 & 550 & 550 & 550 & 550 \\
\hline
\end{tabular}


Table 3: Bitterness evaluation of solid mixture granules of drotaverine $\mathrm{HCl}$

\begin{tabular}{lllllllll}
\hline \multirow{2}{*}{ Volunteers } & \multicolumn{3}{c}{ Drug-rxcipient ratio } & \multicolumn{5}{c}{ Drug-HPMC ratio } \\
\cline { 2 - 8 } & $\mathbf{1 : 1}$ & $\mathbf{1 : 5}$ & $\mathbf{1 : 7 . 5}$ & $\mathbf{1 : 9}$ & $\mathbf{1 : 1}$ & $\mathbf{1 : 5}$ & $\mathbf{1 : 7 . 5}$ & $\mathbf{1 : 9}$ \\
\hline I & 2 & 3 & 1 & 0 & 2 & 2 & 2 & 0 \\
II & 1 & 1 & 0 & 1 & 2 & 1 & 1 & 0 \\
III & 1 & 2 & 0 & 1 & 1 & 2 & 1 & 1 \\
IV & 3 & 1 & 0 & 0 & 3 & 2 & 0 & 0 \\
V & 1 & 2 & 0 & 1 & 2 & 3 & 1 & 0 \\
VI & 2 & 1 & 1 & 0 & 2 & 2 & 2 & 0 \\
\hline
\end{tabular}

0: No bitterness, 1: Threshold bitterness, 2: Very slight bitterness, 3: Slight bitterness

Table 4: Flow parameters for drotaverine $\mathrm{HCl}$ mixtures

\begin{tabular}{llll}
\hline Formulation & $\begin{array}{l}\text { Angle of } \\
\text { repose } \mathbf{~ (}^{\circ} \text { ) }\end{array}$ & $\begin{array}{l}\text { Carr's } \\
\text { index (\%) }\end{array}$ & $\begin{array}{l}\text { Hausner } \\
\text { ratio }\end{array}$ \\
\hline R1 & 20.66 & 10.7 & 1.12 \\
R2 & 21.52 & 13.7 & 1.15 \\
R3 & 20.35 & 11.5 & 1.13 \\
R4 & 22.96 & 7.6 & 1.08 \\
R5 & 21.57 & 9.09 & 1.10 \\
R6 & 23.15 & 8.33 & 1.09 \\
R7 & 20.28 & 7.40 & 1.08 \\
R8 & 21.43 & 9.90 & 1.11 \\
R9 & 22.35 & 6.54 & 1.07 \\
R10 & 20.46 & 14.2 & 1.16 \\
R11 & 21.77 & 13.7 & 1.15 \\
H1 & 21.44 & 14.2 & 1.16 \\
H2 & 20.84 & 11.5 & 1.13 \\
H3 & 22.43 & 7.6 & 1.08 \\
H4 & 22.61 & 10.7 & 1.12 \\
H5 & 23.45 & 8.33 & 1.09 \\
H6 & 21.73 & 7.4 & 1.08 \\
H7 & 20.76 & 9.09 & 1.10 \\
H8 & 21.84 & 13.7 & 1.15 \\
H9 & 22.62 & 11.5 & 1.13 \\
\hline & & & \\
\hline
\end{tabular}

\section{RESULTS AND DISCUSSION}

Rxcipient and HPMC 3 cps were used to mask the taste of drotaverine $\mathrm{HCl}$. Further, these agents may improve the dissolution and release, thereby meeting the ODT requirements of quicker disintegration. Rxcipient is very fine and having large surface area. The drug is adsorbed and distributed onto larger surface area during kneading with solvent, and it also helped in coating the drug particles, thereby aiding in taste masking. Wet granulation method with PVPK-30 as binder in isopropyl alcohol is used as the obtained solid mixture was not having the required compressibility nature.

HPMC is normally used in controlled release formulations. It is hydrophilic in nature and swells with water and releases the drug slowly. Due to its hydrophilic and swelling nature, the solubility and release of sparingly soluble drotaverine $\mathrm{HCl}$ may be improved. Low viscosity grade of HPMC was used in this study such that disintegration and subsequent release of drug are not prolonged.

\section{Optimization of the ratio of drug-carrier solid mixture}

Solid mixtures with the selected carriers were prepared with different drug-carrier ratios and were tested for the taste masking efficiency initially, and only those solid mixtures were further evaluated for the preparation of ODT and subsequent evaluation. The ratio of drugcarrier was evaluated for bitterness of the prepared granules by human volunteers. The results are shown in Table 3.

Bitterness of the drug was effectively masked as per the bitterness scale by the solid mixtures prepared with 1:7.5 ratio of rxcipient and 1:9 ratio of HPMC. Hence, they were considered as the best among the prepared solid mixtures. These ratios were selected for the preparation of ODT of drotaverine $\mathrm{HCl}$ using different superdisintegrants and diluents.

\section{Evaluation of flow properties}

The flow properties of the prepared agglomerates were evaluated using the parameters such as angle of repose, compressibility index, and Hausner ratio for their suitability for direct compression. The parameters were determined and the results are tabulated in Table 4 .

The angle of repose observed was found to be 20.28 lowest for R7 and 23.15 highest for R6. Similarly, the lowest value of 20.76 for $\mathrm{H7}$ and highest value of 22.62 for $\mathrm{H} 9$ were observed. The observed values for angle of repose are lower than $25^{\circ}$ indicating good flow characteristics of the granules.

The values of compressibility index for all varied between 7.4 and 14.2. The observed values are either lower or very near to $15 \%$ indicating good flow characteristics of the granules.

As per standard, values of Hausner ratio observed was between 1.07 and 1.16 which was below 1.18 indicating good flow properties.

\section{Evaluation of the prepared tablets}

The prepared tablets were evaluated for the general properties such as general appearance, hardness, thickness, uniformity of weight, friability, in vitro disintegration time, uniformity of content, fineness of dispersion, in vitro dispersion time, wetting time, in vitro dissolution and in vivo disintegration, and taste evaluation, and the results are shown in Tables 5 and 6.

\section{General appearance}

All the prepared formulations are pale-yellow in color.

\section{Hardness}

The average hardness of all the tablets prepared using the solid mixture of rxcipient or HPMC was in range of $3-5 \mathrm{Kg} / \mathrm{cm}^{2}$. This ensures good handling characteristics of the formulations.

\section{Thickness}

The tablet thickness values were between 5.12 and $5.18 \mathrm{~mm}$.

\section{Friability}

The percentage friability of the tablets prepared using solid mixtures of HPMC and rxcipient was $<1 \%$ in all the formulations, ensuring that the tablets were mechanically stable. All the tablets showed values around $0.67 \%$.

The in vitro dispersion time, disintegration time, and in vivo disintegration time were expressed in $\min$ for these tablets uniformity of weight

All the prepared tablets passed weight variation test, as percentage weight variation was within the pharmacopoeial limits, i.e., $\pm 5 \%$.

\section{In vitro disintegration time}

In line with the IP limits for disintegration of dispersible tablets, orodispersible tablets must disintegrate within $3 \mathrm{~min}$, i.e., $180 \mathrm{~s}$. The prepared tablets with solid mixtures of rxcipient showed the disintegration time in a range of 24-90 s, of which R1 and R10 showed very less disintegration time of 24 and $25 \mathrm{~s}$, respectively. The tablets prepared with HPMC (H1, H2, H3, and H4) showed the disintegration time in the range of 3-10 min. Among the formulations, $\mathrm{H} 2$ has shown less disintegration time of $3.8 \mathrm{~min}$. Hence, to reduce the disintegration time to $<3 \mathrm{~min}$, superdisintegrants were used in the formulations either alone or in combination. The superdisintegrants decreased the disintegration time of $\mathrm{H} 9$ ( $3 \%$ CCS and $3 \%$ SSG) to $32 \mathrm{~s}$ and H8 (3\% CCS and $3 \%$ SSG) to $48 \mathrm{~s}$, indicating that they were suitable as orodispersible tablets. 

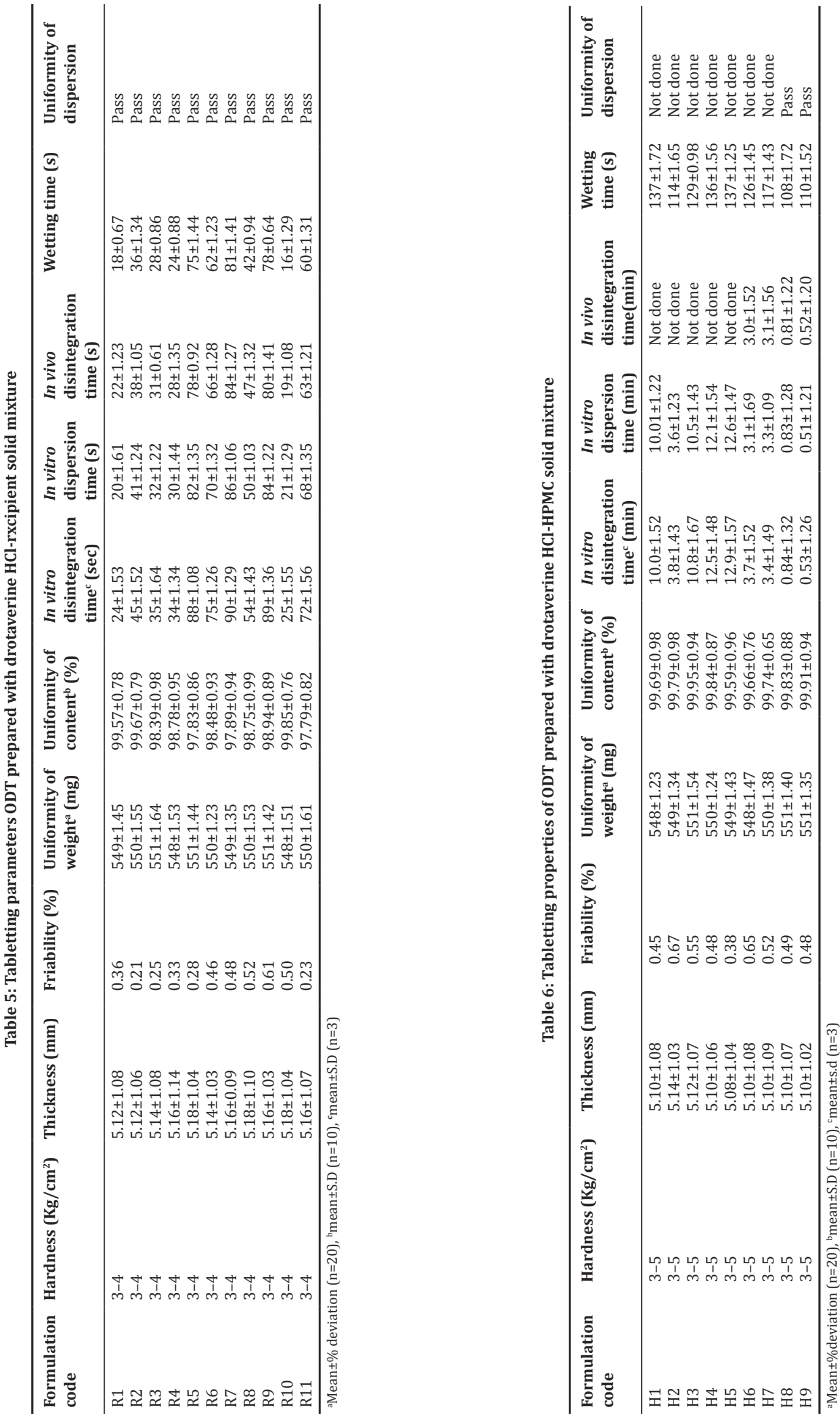
Uniformity of content

The percentage drug content present in all the batches prepared was found to be in the range of $97-99.95 \%$ indicating uniform distribution of drug during granulation process.

\section{Uniformity of dispersion}

All the formulations passed this test as they formed fine dispersion within 3 min and passed through Sieve \#22 without any residue left on the sieve.

\section{In vitro dispersion time}

The tablets showed less in vitro dispersion time. The lowest dispersion time of $20 \pm 1.61 \mathrm{~s}$ for R1 and $0.52 \pm 1.20 \mathrm{~min}(30 \mathrm{~s}$ ) for $\mathrm{H} 9$ was observed. This test was not performed for formulations $\mathrm{H} 1-\mathrm{H} 7$ as they failed to pass the disintegration time.

\section{Wetting time}

Formulations prepared with rxcipient showed wetting time of 16-81 s, and with HPMC, the values were between 108 and 137 s.

\section{In vitro dissolution studies}

The drug dissolution data of the tablets prepared using solid mixtures of rxcipient and HPMC are given in Tables 7-9. The corresponding dissolution profiles of all the prepared tablets and commercial tablet (MF) are shown in Figs. 1 and 2.

From the dissolution studies of tablets R1 to R6, prepared using solid mixture of rxcipient, it was observed that the drug release depended on the superdisintegrant used in the formulation. While croscarmellose sodium (R1 and R2) formulations showed drug release of 100\% in 60 min, SSG (R3 and R4) and crospovidone (R5 and R6) formulations showed $82-87 \%$ and $80-85 \%$ of drug release for $60 \mathrm{~min}$, respectively. Hence, the formulation with CCS was considered as optimum as per goal. Optimization of the concentration of croscarmellose sodium was further studied by varying its concentration between $1 \%$ and $5 \%$ weight of tablet. Complete drug release was observed for R10 at $60 \mathrm{~min}$. R11 formulation with CCS 5\% released $96 \%$ of drug in 60 min. Increase in concentration of CCS reduced the drug release which may be due to increased viscosity of CCS. Hence, the optimum concentration of CCS was fixed as $4 \%$ of tablet weight. When compared with the marketed formulation which has shown drug release of $85 \%$ in $60 \mathrm{~min}$, the R10 formulation has shown more drug release, i.e., $100 \%$ in $60 \mathrm{~min}$. From the dissolution studies of tablets formulated using HPMC ( $3 \mathrm{cps}$ ), it was observed that the formulations prepared using various concentrations (1-4\%) of CCS (H1-H4) showed 70-91\% of drug release, among which $\mathrm{H} 2$ formulation (3\% of CCS) has shown $90 \%$ of drug release in $60 \mathrm{~min}$. However, the disintegration time of $\mathrm{H} 2$ was found to be 3.8 min which was not within the limits. Hence, to enhance the disintegration as well as dissolution, a combination of superdisintegrants (H5-H9) was used, and the drug release for $\mathrm{H} 5, \mathrm{H} 6, \mathrm{H} 7, \mathrm{H} 8$, and $\mathrm{H} 9$ was $40 \%, 82.8 \%, 99.8 \%$, $99.5 \%$, and $99.9 \%$, respectively, for $60 \mathrm{~min}$. By considering the values of disintegration time and dissolution profile of all the formulations, H9 satisfied the criteria of disintegration time (32 s) and has shown good dissolution profile.

Hence, the $\mathrm{H} 9$ formulation consisting of $3 \%$ CCS, 3\% SSG, and 2\% MCC as superdisintegrants is selected as the best formulation. When compared to the marketed formulation which has shown drug release of $85 \%$ in $60 \mathrm{~min}$ and $99.9 \%$ in $90 \mathrm{~min}$, H9 formulation has shown more drug release, i.e., $99.5 \%$ in $60 \mathrm{~min}$. By considering all the parameters

Table 7: Cumulative $\%$ drug released versus time from ODT prepared with drotaverine HCl-rxcipient solid mixture (mean \pm S.D $n=3$ )

\begin{tabular}{|c|c|c|c|c|c|c|c|}
\hline \multirow[t]{2}{*}{ Time (min) } & \multicolumn{7}{|c|}{ Cumulative \% drug released } \\
\hline & R1 & $\mathbf{R} 2$ & R3 & R4 & R5 & R6 & MF \\
\hline 5 & $33.5 \pm 0.75$ & $40 \pm 0.53$ & $45.5 \pm 0.61$ & $39.5 \pm 1.26$ & $53.5 \pm 1.21$ & $47.4 \pm 1.06$ & $49.6 \pm 1.13$ \\
\hline 10 & $48.2 \pm 0.65$ & $52.7 \pm 0.49$ & $59.5 \pm 1.13$ & $48.2 \pm 1.29$ & $59.2 \pm 1.05$ & $60.2 \pm 0.94$ & $55.0 \pm 1.21$ \\
\hline 15 & $69.2 \pm 0.84$ & $67.5 \pm 1.2$ & $66.2 \pm 0.94$ & $59.2 \pm 0.97$ & $64.7 \pm 0.94$ & $65.2 \pm 0.83$ & $61.2 \pm 0.58$ \\
\hline 30 & $88.5 \pm 1.02$ & $84.8 \pm 0.95$ & $72.8 \pm 0.86$ & $66.7 \pm 0.96$ & $72.4 \pm 0.67$ & $75.1 \pm 0.75$ & $72.3 \pm 0.99$ \\
\hline 45 & $93.7 \pm 1.21$ & $99.5 \pm 0.86$ & $83.2 \pm 0.72$ & $73.5 \pm 0.61$ & $79.2 \pm 0.83$ & $78.7 \pm 0.94$ & $80.5 \pm 1.08$ \\
\hline 60 & $99.9 \pm 0.95$ & $100 \pm 1.11$ & $87.4 \pm 1.16$ & $82.2 \pm 0.51$ & $81.0 \pm 0.49$ & $85.2 \pm 0.76$ & $85.0 \pm 1.03$ \\
\hline 90 & & & $98.5 \pm 0.42$ & $99.5 \pm 0.83$ & $82.1 \pm 0.59$ & $95.5 \pm 1.09$ & $99.9 \pm 0.86$ \\
\hline
\end{tabular}

Table 8: Cumulative $\%$ drug released versus time from ODT prepared with drotaverine HCl-rxcipient solid mixture (mean \pm S.D n=3)

\begin{tabular}{|c|c|c|c|c|c|}
\hline \multirow[t]{2}{*}{ Time (min) } & \multicolumn{5}{|c|}{ Cumulative $\%$ drug released } \\
\hline & R7 & R8 & R9 & R10 & R11 \\
\hline 5 & $30.7 \pm 1.10$ & $47.4 \pm 0.99$ & $40.0 \pm 0.94$ & $33.5 \pm 0.46$ & $31.6 \pm 0.86$ \\
\hline 10 & $56.0 \pm 1.11$ & $56.7 \pm 0.64$ & $52.7 \pm 0.86$ & $48.2 \pm 0.83$ & $45.2 \pm 0.48$ \\
\hline 15 & $61.3 \pm 1.04$ & $64.5 \pm 0.37$ & $67.5 \pm 0.84$ & $69.2 \pm 0.99$ & $56.8 \pm 0.78$ \\
\hline 30 & $72.5 \pm 1.03$ & $77.8 \pm 0.83$ & $84.8 \pm 0.76$ & $88.5 \pm 0.94$ & $75.3 \pm 0.84$ \\
\hline 45 & $78.1 \pm 1.06$ & $81.5 \pm 0.91$ & $97.5 \pm 0.84$ & $93.7 \pm 1.09$ & $91.6 \pm 0.46$ \\
\hline 60 & $82.4 \pm 1.04$ & $86.0 \pm 0.64$ & $99.9 \pm 0.76$ & $100 \pm 1.02$ & $95.6 \pm 0.38$ \\
\hline 90 & $96.7 \pm 1.01$ & $99.5 \pm 0.84$ & - & - & $99.5 \pm 0.94$ \\
\hline
\end{tabular}

Table 9: Cumulative $\%$ drug released versus time from ODT prepared with drotaverine HCl-HPMC solid mixture $(m e a n \pm S . D n=3)$

Time (min) Cumulative \% drug released

\begin{tabular}{|c|c|c|c|c|c|c|c|c|c|}
\hline & H1 & H2 & H3 & H4 & H5 & H6 & H7 & H8 & H9 \\
\hline 5 & $19.5 \pm 1.02$ & $26.5 \pm 0.98$ & $19.2 \pm 0.86$ & $18.3 \pm 0.76$ & $6.4 \pm 0.76$ & $17.5 \pm 0.94$ & $29.4 \pm 0.81$ & $30.2 \pm 0.51$ & $31.2 \pm 0.64$ \\
\hline 10 & $32.1 \pm 1.31$ & $53.6 \pm 0.96$ & $29.4 \pm 0.83$ & $28.8 \pm 0.94$ & $8.67 \pm 0.94$ & $22.0 \pm 0.86$ & $34.2 \pm 0.86$ & $39.1 \pm 0.64$ & $42.9 \pm 0.68$ \\
\hline 15 & $43.8 \pm 1.11$ & $68.5 \pm 0.94$ & $35.5 \pm 0.84$ & $39.1 \pm 0.97$ & $12.2 \pm 0.93$ & $48.6 \pm 0.83$ & $42.9 \pm 0.76$ & $46.4 \pm 0.64$ & $54.6 \pm 0.55$ \\
\hline 30 & $51.4 \pm 1.09$ & $76.5 \pm 0.92$ & $70.1 \pm 0.89$ & $65.8 \pm 0.93$ & $21.4 \pm 0.82$ & $63.4 \pm 0.88$ & $60.1 \pm 0.72$ & $63.7 \pm 0.53$ & $66.8 \pm 0.58$ \\
\hline 45 & $60.1 \pm 1.06$ & $81.1 \pm 0.91$ & $80.5 \pm 0.87$ & $75.8 \pm 0.94$ & $31.7 \pm 0.73$ & $74.2 \pm 0.72$ & $89.0 \pm 0.84$ & $86.4 \pm 0.58$ & $79.9 \pm 0.53$ \\
\hline 60 & $72.5 \pm 1.05$ & $90.7 \pm 0.94$ & $90.1 \pm 0.83$ & $83.2 \pm 0.73$ & $40.1 \pm 0.84$ & $82.8 \pm 0.76$ & $99.8 \pm 0.89$ & $99.5 \pm 0.64$ & $99.9 \pm 0.59$ \\
\hline 90 & $77.4 \pm 1.04$ & $99.6 \pm 0.93$ & $97.8 \pm 0.74$ & $85.4 \pm 0.88$ & $56.2 \pm 0.94$ & $99.2 \pm 0.64$ & & & \\
\hline
\end{tabular}


such a in vitro disintegration time, in vivo disintegration time, wetting time, dispersion time, and dissolution profile of all the tablets prepared using rxcipient or HPMC 3cps, the formulations R10 and $\mathrm{H} 9$ had shown best results. Hence, they are considered as optimized formulations. However, HPMC high viscosity materials are normally used in controlled release formulations. It is hydrophilic in nature and swells with water. Very low viscosity grade of HPMC was used such that disintegration and subsequent release was not hindered. Due to the swelling nature, it draws water and the disintegration gets improved which is very much required for ODT. At the same time, the drug particles are surrounded by HPMC and the release is also retarded, whereby bitterness of the drug may not be felt. Due to swelling nature, the solubility and release of sparingly soluble drotaverine $\mathrm{HCl}$ may be improved which resulted in faster dissolution. Although faster disintegration and dissolutions are obtained with rxcipient because of the very large surface area of the material (very fine powder), the mouth feel was not as pleasant as that of formulations with HPMC. Hence, considering all the above H9 formulation with HPMC 3cps was selected.

\section{In vivo disintegration and taste evaluation}

The optimized formulations were given to a panel of healthy human volunteers for taste masking evaluation using time intensity method, and the results are shown in Table 10.

From Table 10, the tablets prepared using rxcipient showed some grittiness compared to tablets prepared using HPMC 3 cps. This may be due to mannitol in the drug-carrier solid mixture during the preparation of the tablets using rxcipient. Although it is showing grittiness, mannitol (sweet taste) was added to enhance the taste masking capacity of rxcipient as the taste masking capacity of it was less compared to HPMC.

\section{Drug-excipient compatibility studies}

The characterization of drotaverine $\mathrm{HCl}$ in ODT was carried out using DSC, XRD, and FTIR techniques for any changes in its physical state or chemical interactions if any between the drug and melting agent.

\section{DSC analysis}

The DSC thermograms of pure drug and optimized formulation are shown in Fig. 3. The DSC thermogram of pure drotaverine $\mathrm{HCl}$ exhibited a sharp endothermic peak at $215.12^{\circ} \mathrm{C}$ corresponding to its melting point, indicating its crystalline nature.

There is a shift in the melting peak of drotaverine $\mathrm{HCl}$ in the optimized formulations $\mathrm{H} 9$ to $56.32^{\circ} \mathrm{C}-134.21^{\circ} \mathrm{C}$. The shift observed in the melting peak of drotaverine $\mathrm{HCl}$ in the optimized formulation may be due to physical interaction between the drug and excipient. Compared to pure drug, the melting peak was broadened to some extent in the formulation which may be due to changes in its crystalline form. The low melting point of the excipients might have influenced the shift in the melting point of the drug in the formulation.

\section{XRD analysis}

The XRD of pure drug drotaverine $\mathrm{HCl}$ and optimized formulation are shown in Fig. 4. XRD diffractograms for pure drug and formulation were studied for comparison. The diffractogram of drotaverine $\mathrm{HCl}$ showed characteristic sharp intensity diffraction peaks at $2 \theta$ values of $14.5^{\circ}$, $22^{\circ}, 44^{\circ}, 65^{\circ}$, and $77^{\circ}$, which reflected the crystalline nature of drug. The optimized formulation $\mathrm{H} 9$ showed diffraction peaks at respective $2 \theta$ values of pure drotaverine $\mathrm{HCl}$ although their relative intensities were reduced, suggesting reduced degree of crystallinity of drug in these formulations.

\section{FTIR spectroscopy}

FTIR analysis for pure drug and its mixtures was carried out. The drug and polymers did not produce major shift in principal peaks of drotaverine $\mathrm{HCl}$, indicating no interaction. Thus, FTIR spectral analysis proved the compatibility between drug and carriers.
Table 10: Taste evaluation and mouth feel of optimized formulations

\begin{tabular}{lllllll}
\hline Volunteers & I & II & III & IV & V & VI \\
\hline Formulation R10 & & & & & & \\
$\quad$ Bitterness & 1 & 0 & 0 & 1 & 1 & 0 \\
$\quad$ Mouth feel & - & - & - & - & -- & - \\
Formulation H9 & & & & & & \\
$\quad$ Bitterness & 0 & 0 & 1 & 0 & 0 & 1 \\
$\quad$ Mouth feel & - & + & + & + & - & + \\
\hline
\end{tabular}

0: No bitterness, 1: Threshold bitterness, + : Smooth and pleasant, -: Gritty and pleasant feel

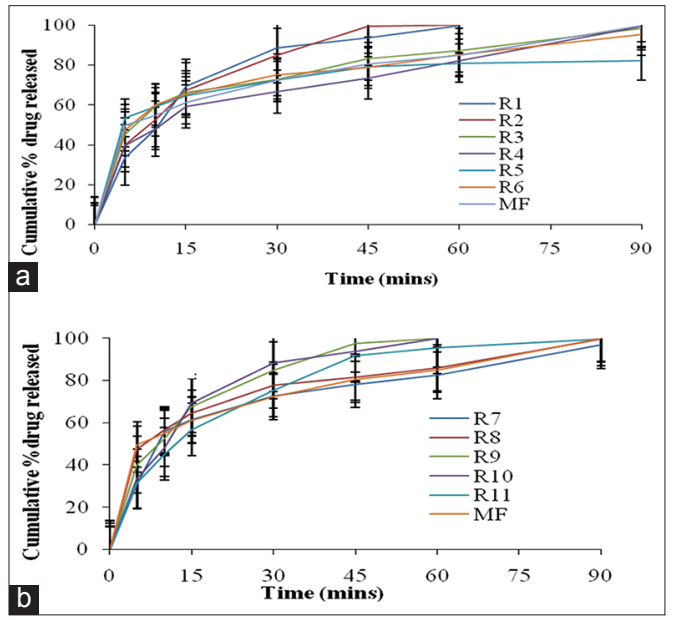

Fig. 1: Dissolution profiles of drotaverine HCl ODT using Rxcipient solid mixture (a) R1-R6, (b) R7-R11 and marketed formulation

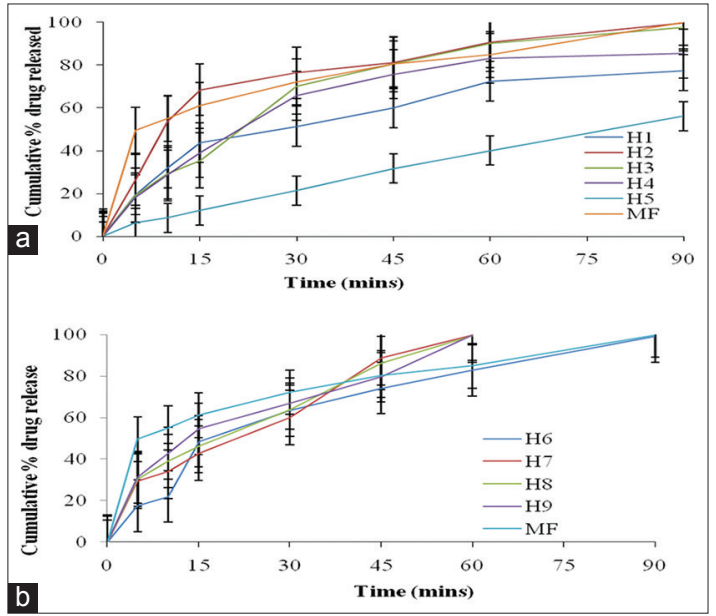

Fig. 2: Dissolution profiles of drotaverine HCl ODT using HPMC solid mixture (a) H1-H5, (b) H6-H9 and marketed formulation

The FTIR spectra of pure drug and its combinations are presented in Figs. 5 and 6.

\section{CONCLUSION}

From the results of the study, drug-carrier solid mixtures of rxcipient and HPMC affect the physicochemical characteristics of drotaverine $\mathrm{HCl}$ orally disintegrating tablets. Based on pre- and post-compression evaluations, formulations R10 and H9 were the best formulations. Formulation R10 using rxcipient showed the fastest wetting time $(16 \pm 1.29 \mathrm{~s})$, in vitro disintegration time $(25 \pm 1.55 \mathrm{~s})$, and in vitro dispersion time $(21 \pm 1.29 \mathrm{~s})$ among all formulations. Formulation H9 using HPMC showed the fastest wetting time (110 $\pm 1.52 \mathrm{~s})$, in vitro 


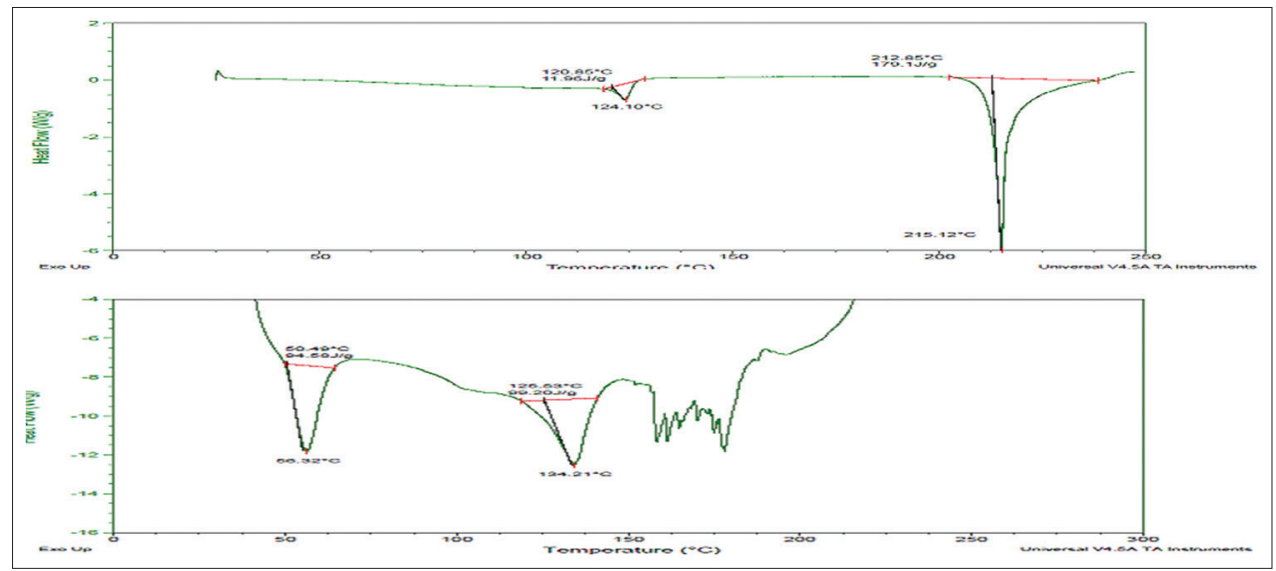

Fig. 3: Differential scanning calorimetry thermograms of (a) drotaverine $\mathrm{HCl}$ and (b) $\mathrm{H} 9$ tablet

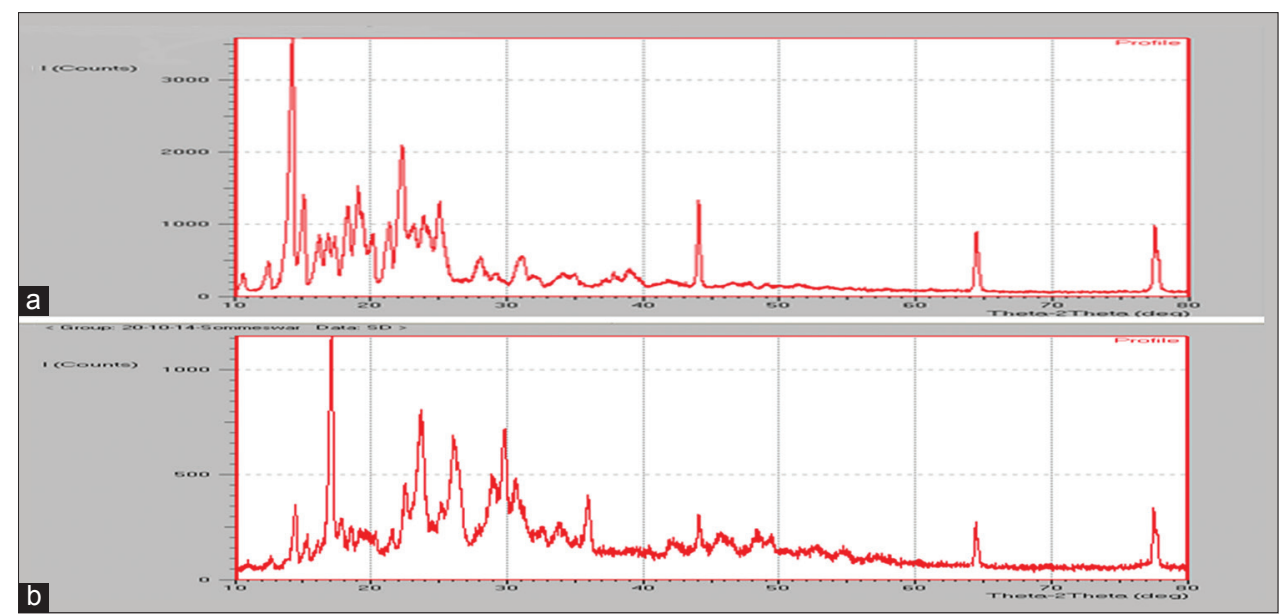

Fig. 4: X-ray diffractograms of (a) drotaverine $\mathrm{HCl}$ and (b) formulation $\mathrm{H9}$

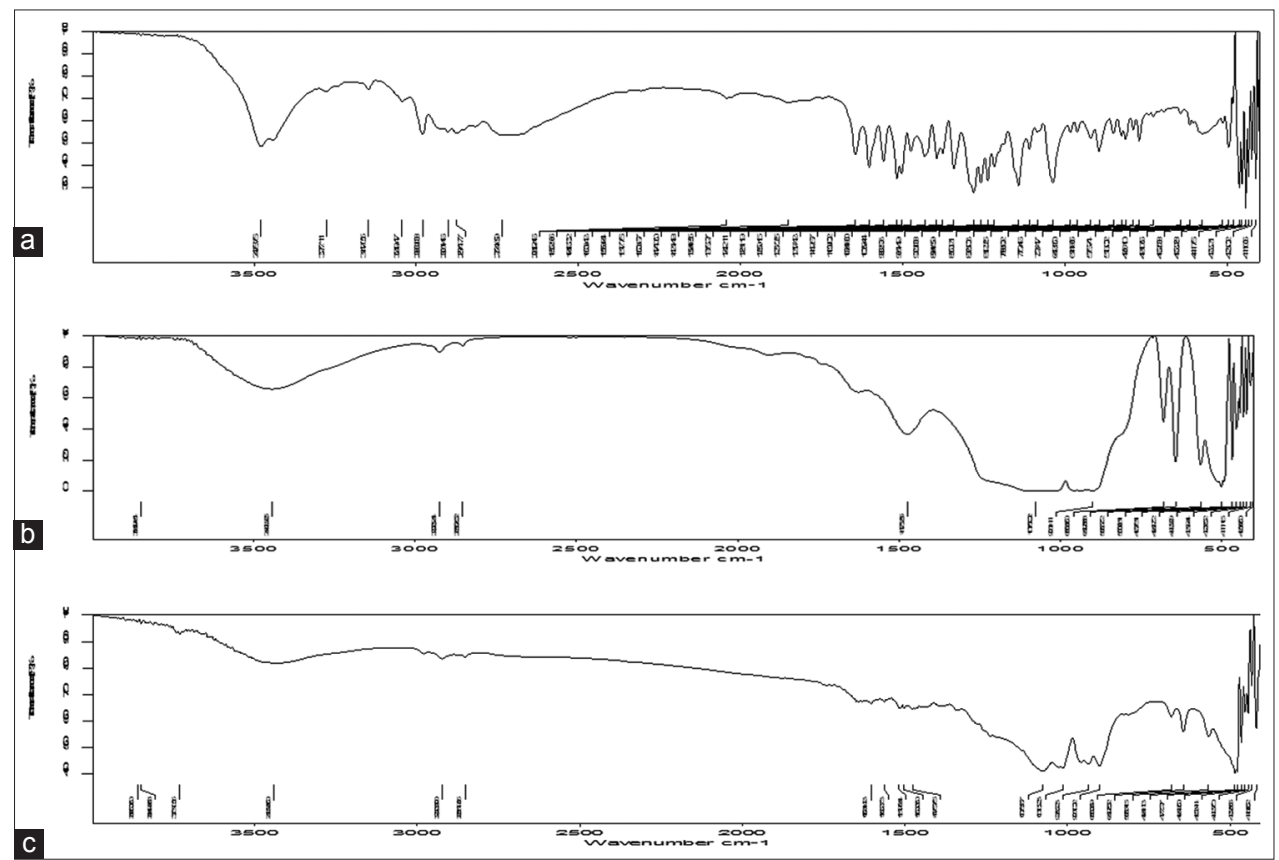

Fig. 5: Fourier-transformation infrared spectra of (a) drotaverine $\mathrm{HCl}$, (b) Rxcipient, and (c) hydroxypropyl methylcellulose

disintegration time $(0.53 \pm 1.26 \mathrm{~min})$, and in vitro dispersion time $(0.51 \pm 1.21 \mathrm{~min})$ among all formulations. The faster disintegration time of drotaverine $\mathrm{HCl}$ orally disintegrating tablets of R10 and H9 caused a significant impact in dissolution characteristics. The optimized 


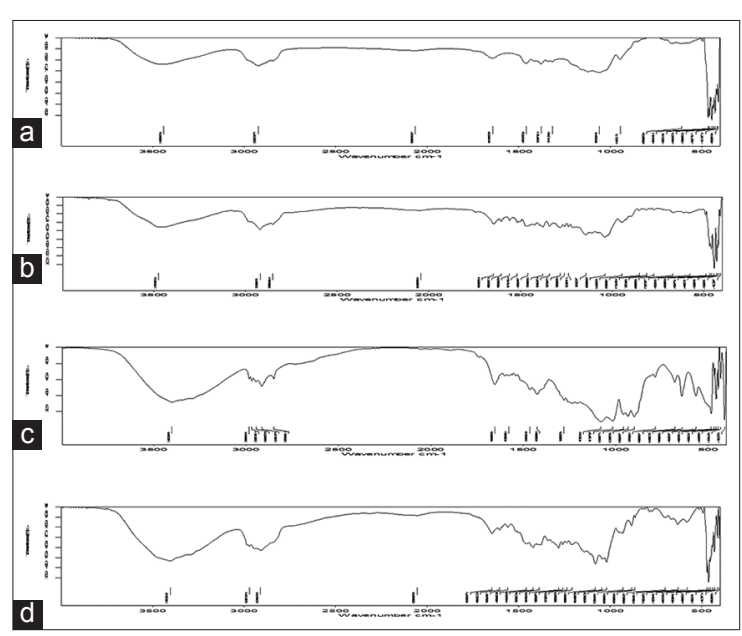

Fig. 6: Fourier-transformation infrared spectra of (a) drotaverineRxcipient solid mixture (1:7.5), (b) drotaverine-hydroxypropyl methylcellulose solid mixture (1:9), (c) R10 tablet, and (d) H9 tablet

formulations have shown maximum drug release in $60 \mathrm{~min}$ and masked the bitterness of the drug. From DSC, XRD, and FTIR studies, no chemical changes were observed in the drug with changes in crystallinity of the drug. As there are no reports on taste masked ODT of drotaverine $\mathrm{HCl}$ with HPMC and rxcipient, therefore the present work can be considered as a significant contribution. Based on the results, it can be concluded that HPMC and rxcipient can be suitably used for taste masking of drotaverine $\mathrm{HCl}$.

\section{ACKNOWLEDGMENT}

The author Dr. K. Hari is thankful to Biocon Ltd., for drotaverine $\mathrm{HCl}$, and to Dr. Reddy's Laboratories for HPMC 3cps, rxcipient ${ }^{\circledast}$ FM1000 for providing the gift samples. The author is thankful to the Department of Pharmaceutical Technology, A. U. College of Pharmaceutical Sciences, Andhra University, Visakhapatnam, India, who graciously supported for doing work.

\section{AUTHOR'S CONTRIBUTIONS}

Dr. K. Hari performed experiments, interpreted data, wrote the manuscript, and acted as corresponding author. Dr. S. Rajeswari has helped in the development of work and manuscript preparation. Moreover, Prof. K. V. Ramana Murthy had supervised the study and helped to evaluate and edit the manuscript.

\section{CONFLICT OF INTEREST}

There is no conflict of interests.

\section{REFERENCES}

1. Sabitri B, Snehamayee M. Recent approaches of solid dispersion: A new concept toward oral bioavailability. Asain J Pharm Clin Res 2018;11:72-8.

2. Anusha P, Nirajana A, Mohammed S, Jilani S, Murali C, Harish G.
Development and evaluation of drotaverine taste masked tablets with improved dissolution efficiency using sold dispersion technique. India J Res PB 2013;1:275-80.

3. Ujwala B, Dinesh S, Sarika Z, Varsha K, Nanda R. Development and evaluation of drotaverine taste masked tablets with improved dissolution efficiency using sold dispersion technique. Res J Pharm Tech 2014;7: 301-6.

4. Srikanth M, Uhumwangho M, Sunil S, Sreenivasa N, Ravi C, Murthy KR. Design and evaluation of taste masked drotaverine $\mathrm{HCl}$ orodispersible tablets using polymethacrylate polymers. Pharm Lett 2010;2:223-31.

5. Pandey B, Mallik S, Ahmad S. Coprocessing of superdisintegrants for drug release of taste masked drotaverine $\mathrm{HCl}$. Novel Sci IJPS 2012;1:758-63.

6. Fulla M, Israa H, Samira F. Taste masking of prifinum bromide in orodispersible tablets. Int J Pharm Pharm Sci 2014;6:315-9.

7. Shivangi S, Navneet V. Taste masked orodispersible tablets. A highly patient compliant dosage form. Asian J Pharm Clin Res 2016;9:385-91.

8. Aziz M, Salahuddin M, Ghulam M, Abdul R. Formulation and in-vitro evaluation of deferasirox oro-dispersible tablets. Int J Pharm Pharm Sci 2014;6:203-9

9. Raghavendra N, Mahesh K, Srikanth M, Kistayya C, Mahipal B. Development and evaluation of fast dissolving tablets of fosinopril by sublimation method. Int J Pharm Sci Drug Res 2012;4:230-5.

10. Kumar R, Swati P, Patil M, Sachin R, Mahesh S. Formulation evaluation of mouth dissolving tablets of fenofibrate using sublimation technique. Int J Chem Tech Res 2009;1:840-50.

11. Uddhav B, Kishore G, Nancy P, Sanjeevani A, Shalaka D. Formulation and evaluation of sublimed fast melt tablets of levocetirizine dihydrochloride. Int J Pharm Sci Res 2010;2:76-80.

12. Madgulkar A, Kadam S, Pokharkar V. Studies on formulation development of mucoadhesive sustained release itraconazole tablet using response surface methodology. AAPS PharmSciTech 2008;9:998- 1005.

13. USP30-NF25. The Official Compendia of Standards. The United States Pharmacopoeial Convention. Powder Flow. (e book); 2007. p. 643.

14. TRAIN D. Some aspects of the property of angle of repose of powders. J Pharm Pharmacol 1958;10:127-35T.

15. USP30-NF25. The Official Compendia of Standards. The United States Pharmacopoeial Convention. Bulk Density and Tapped Density (e book); 2007. p. 242.

16. Craick DJ. The flow properties of starch powders and mixtures. J Pharm Pharmacol 1958;10:10

17. Indian Pharmacopoeia. Government of India, Ministry of Health and Family Welfare, the Indian Pharmacopeia Commission. Ghaziabad, India: Indian Pharmacopoeia; 2010. p. I, 187-93.

18. Bi YX, Sunada H, Yonezawe Y, Danzo K. Evaluation of rapidly disintegrating tablets. Drug Dev Ind Pharm 1999;25:571-81.

19. Sivaprasad S, Ahad HA, Sreenivasulu R, Reddy BK, Mahesh CH, Kranthi G, et al. Novel approach in designing of mouth dissolving tablets for bitter drugs taking clozapine as model drug. Pharm Lett 2011;3:113-20.

20. Subrahmanian S, Sankar V, Asha A. Formulation and evaluation of cetrizine dihydrochloride orodispersible tablet. Pak J Pharm Sci 2010;23:232-5.

21. Abdelbary G, Eouani C, Prinderre P, Joachim J, Reynier J, Piccerelle P. Determination of the in vitro disintegration profile of rapidly disintegrating tablets and correlation with oral disintegration. Int $\mathbf{J}$ Pharm 2005;292:29-41.

22. Uchida T, Nakamura T, Tanigake A. The effect of various substances on the suppression of the bitterness of quinine-human gustatory sensation, binding and taste sensor studies. Chem Pharm Bull (Tokyo) 2002;50:1589-93. 